RESENHA

\title{
The Nature of Technology - What it is and how it evolves
}

\section{W. Brian Arthur}

Nova York: Free Press, 2009. 246 p.

Newton Paulo Bueno

Departamento de Economia, Universidade Federal de Viçosa

\section{A natureza da tecnologia segundo W. Brian Arthur}

Brian Arthur é um dos mais influentes economistas atuais. Sua principal contribuição é a de ter trazido para a economia alguns dos principais insights da moderna ciência da complexidade, o que lhe valeu a indicação para primeiro diretor do mais importante núcleo internacional de pesquisas interdisciplinares em sistemas complexos: o Programa de Economia do Instituto de Santa Fé. Sua primeira e mais conhecida contribuição seminal nesse campo interdisciplinar foi a de mostrar que, devido à existência de ciclos de retroalimentação positiva no processo, sistemas econômicos podem ter sua matriz tecnológica trancada (locked-in) em tecnologias inferiores.' A trajetória tecnológica de cada sistema econômico assim será dependente da trajetória, no sentido de que eventos históricos fortuitos que deslocam momentaneamente a preferência dos usuários para uma certa tecnologia, podem fazer com que outras opções, eventualmente mais eficientes, deixem de fazer parte do repertório futuro de técnicas disponíveis para a economia. Como na evolução biológica, a teoria ajuda a compreender os processos básicos de como a tecnologia evolui, mas, por ser este também um fenômeno complexo, não é suficiente para fazer previsões específicas sobre quais tecnologias prevalecerão no futuro. A segunda contribuição seminal, mas talvez menos conhecida, foi mostrar que o modo como agentes formam suas

1 W.B. Arthur, "Competing technologies, increasing returns, and lock-in by historical events", The Economic Journal, 99, 1989. 
expectativas econômicas é também um processo complexo, no sentido de que cada agente dispõe de um conjunto de regras para formular suas previsões, as quais são selecionadas por um processo indutivo, por meio do qual eles se adaptam às condições vigentes em seu ambiente. Essa ideia que tem sido aplicada em textos importantes para o mercado financeiro ${ }^{2}$ foi formulada para entender o prosaico problema de como as pessoas formavam expectativas sobre o número de pessoas que frequentam o bar favorito de Arthur - o El Farol - em finais de semana. ${ }^{3}$ Se achassem que um número excessivo compareceria, a maioria das pessoas deixaria de ir ao bar em um determinado final de semana; mas, se a previsão fosse de menor comparecimento do que um certo limiar, a maioria compareceria. O problema então era que, se fossem formadas de modo homogêneo, como postulado pela hipótese de expectativas racionais, as expectativas seriam sempre autoinvalidadas, visto que previsões de baixo comparecimento levariam à frequência indesejavelmente alta e vice-versa. Usando simulaçôes em computador, Arthur mostrou que isso na verdade não ocorre: as pessoas têm diversos modelos de previsão e selecionam individualmente aqueles que passam no teste de realismo; as simulaçôes mostraram, de forma um tanto surpreendente, que, selecionando modelos distintos, a taxa de comparecimento acabará convergindo para os níveis que a maioria considera atrativo. Em minha opinião, acho difícil superestimar essa contribuição e penso que muitos frutos provavelmente advirão dela para a teoria econômica no futuro próximo. A terceira contribuição seminal é dada nesse livro. Em uma discussão essencialmente econômica, mas empregando conceitos da ciência da complexidade criados em outros campos, como na física, na matemática e na biologia, Arthur discute alguns dos principais quebra-cabeças colocados pela relação entre economia e tecnologia no mundo moderno. Por exemplo, quais são as forças que dirigem o processo de inovação econômica? Será o processo "puxado" pela demanda dos consumidores finais de bens, ou "empurrado" pelo estímulo da redução de custos? Poderão os governos nacionais de países em desenvolvimento fazer alguma coisa para aumentar a taxa de inovação em suas economias? Qual o significado exato de tecnologia e como ela se desenvolve? Comecemos esta resenha pela última questão, advertindo o leitor de que não tentarei traduzir alguns dos novos termos e conceitos usados pelo autor, como deep crafting e structural deepening, os quais certamente farão parte do estado da arte na literatura sobre tecnologia no futuro próximo.

\footnotetext{
2 W.B. Arthur, "Complexity in economics and financial markets", Complexity, v.1, n.1, abr., 1995.

3 W.B. Arthur, "Inductive behavior and bounded rationality", American Economic Review, 84, maio, 1994.
} 


\section{0 que é, como surge e se desenvolve a tecnologia?}

As definições usuais sobre tecnologia - por exemplo, a de ser a coleção de artefatos e práticas de engenharia disponível para uma sociedade - captam evidentemente aspectos do conceito, mas deixam de fora um ponto fundamental enfatizado por Arthur, a saber, o de que a tecnologia consiste essencialmente na captura de um fenômeno físico e sua colocação em uso para atender propósitos humanos; a tecnologia seria então uma espécie de programação da natureza.

Elas consistem de partes ou módulos os quais se constituem em building blocks para futuras tecnologias, as quais consistirão assim em grande parte recombinaçôes das tecnologias atualmente existentes. Mas como exatamente surgem novas tecnologias a partir dos building blocks existentes?

No capítulo 6, Arthur mostra que, embora possam surgir de três maneiras básicas - como soluçôes de problemas de engenharia, de invenções não deliberadas ou de invençōes que solucionam problemas técnicos usando novos princípios -, a característica fundamental do processo é que elas surgem das tecnologias existentes, as quais fornecem as funçôes necessárias para que os novos elementos possam funcionar. Em muitos casos, fornecem também o estímulo para o surgimento desses novos elementos (cap. 7). Isso pode correr por meio da explicitação da necessidade de substituição de componentes por outros mais resistentes ou mais baratos, ou por meio do que o autor chama de structural deepening, em que subsistemas são adicionados ao sistema original para superar suas limitações, por exemplo a vulnerabilidade a choques externos. Esses subsistemas adicionam profundidade e sofisticação de desenho às estruturas originais, o que as torna progressivamente mais complexas.

Uma questão importante para o desenho de políticas de estímulo a inovações é como criar um ambiente favorável ao seu surgimento e desenvolvimento. Para Arthur, esses ambientes se caracterizam por favorecerem o que ele chama de deep crafting, um conceito próximo ao de learning by doing. É da interação de pessoas que detêm conhecimento técnico de diferentes áreas, encontrando-se muitas vezes informalmente pelos corredores, e que estão lutando com os mesmos problemas, que surgem novas formas de combinar tecnologias existentes para criar produtos que antes não existiam nem mesmo na mente do mais high-tech dos consumidores.

O processo de deep crafting, entretanto, é sutil. Dificilmente se pode esperar que investimentos governamentais direcionados para criar, por exemplo, polos tecnológicos com objetivos comerciais específicos possam vir a ser muito eficazes. O processo 
para ser bem-sucedido deve necessariamente conter elementos de auto-organização, ou, como Arthur gosta de lembrar, de autopoiesis. A história dos modernos polos tecnológicos é absolutamente clara a respeito. Embora a intencionalidade possa ter um papel desencadeador no processo, como no caso da Universidade de Stanford para a criação do Vale do Silício, as grandes inovaçôes surgiram de iniciativas individuais descentralizadas, que conseguiram combinar criativamente tecnologias já existentes.

A inovação tecnológica, o principal motor do desenvolvimento econômico, para resumir o argumento, ocorre por meio de quatro mecanismos relativamente independentes. Primeiro, consiste de soluções incrementais a problemas de engenharia do produto, os milhares de pequenos avanços técnicos que se acumulam e avançam a cada momento, a best practice; segundo, ela consiste de inovaçōes radicais trazidas pelo processo de invenção; e terceiro, consiste de novas tecnologias desenvolvidas a partir do aperfeiçoamento de suas partes internas ou pela adição de novos subsistemas em domínios tecnológicos que transformam radicalmente indústrias já existentes, como no caso do sistema bancário, ou criam indústrias inteiramente novas, como a da biotecnologia.

Dizer que a tecnologia em grande parte cria a si própria, no sentido de que novas tecnologias resultam da recombinação das já existentes, não significa evidentemente que a demanda pelos produtos cuja produção ela viabiliza não tenha papel no processo. No capítulo 9, Arthur mostra que elas só aparecerão se existir uma demanda por eles, embora "demanda" não seja um bom termo, porque, por exemplo, jamais tinha existido uma demanda por computadores com interface gráfica antes que Steve Jobs criasse o Macintosh. O autor por isso prefere usar a ideia de nichos de oportunidade. A maioria desses nichos não são criados a partir de necessidades humanas insatisfeitas, mas das próprias necessidades da tecnologia. As razões para isso são basicamente duas. Primeiro, cada tecnologia em uso pela sua própria existência abre oportunidades para o desenvolvimento de novas combinações capazes de satisfazer as necessidades que ela supre de formas mais baratas e eficientes. Segundo, cada tecnologia requer tecnologias de suporte para produzir e manter seus componentes, aperfeiçoar seu desempenho e organizar a produção e distribuição dos produtos finais que ela gera. Cada uma dessas tecnologias, por sua vez, requer suas próprias tecnologias de suporte. $\mathrm{O}$ automóvel no início do século XX, por exemplo, criou a necessidade de uma série de tecnologias de suporte que se constituíram em nichos de oportunidade, como a produção em linhas de montagem e o refino de gasolina. A tecnologia de produção de gasolina, por sua vez, abriu novas oportunidades no campo de prospecção de petróleo. 
Tais processos podem ser estimulados pela adoção de políticas industriais e, em caso positivo, quais seriam as características essenciais dessas políticas? Para os países em desenvolvimento, especificamente, a lição principal do livro é que, em primeiro lugar, os governos deveriam concentrar seus esforços em estimular o surgimento de empresas comerciais capazes de gerar inovaçôes e criação de ciência básica, em vez de apoiar a produção de bens comercializáveis. Em segundo lugar, visto que no mundo atual a riqueza de um país não advém da posse de recursos, mas da expertise tecnológica, os governos deveriam focalizar seus investimentos em educação tecnológica.

\section{Conclusão}

A tecnologia consiste em última instância na programação da natureza para satisfazer as necessidades humanas, mas o fato de que grande parte dessas necessidades são criadas pela própria tecnologia torna o mundo novo criado pela tecnologia moderna psicologicamente desconfortável para a maioria das pessoas. E isso não exatamente porque tememos que ela cause novos e mais perigosos problemas para cada um dos problemas que ela resolve, mas basicamente porque ela progressivamente nos afasta do ambiente natural que nos é familiar; nossas maiores esperanças encontram-se atualmente na tecnologia, mas nossa confiança instintiva ainda está na natureza. Por exemplo, tememos intuitivamente as consequências imprevisíveis de tecnologias "antinaturais" como as terapias baseadas na utilização de célulastronco, ou o desenvolvimento de alimentos geneticamente modificados? As ideias do novo livro de Brian Arthur resenhadas neste texto não nos ajudam a responder a essas questôes, mas dão pistas importantes para melhor compreendermos e talvez, pelo menos em alguma medida, controlarmos a dinâmica desse mundo novo em que estamos inescapavelmente inseridos. A teoria econômica, por exemplo, já está começando a se adaptar para responder às novas questôes com que temos de lidar:

"[assuming] that the object it studies is not a system at equilibrium, but an evolving, complex system whose elements - consumers, investors, firms, governing authorities - react to the patterns these elements create. Its standard doctrines were built upon bedrock principles of predictability, order, equilibrium, and the exercise of rationality; and this suited an economy that consisted of bulk-process technologies that remained much the same from year to year. But as the economy becomes more combinatorial and technology more open, new principles are entering the 
RESENHA

foundations of economics. Order, closedness, and equilibrium as ways of organizing explanations are giving way to open-endedness, indeterminacy, and the emergence of perpetual novelty" (p. 211).

Esse livro é um importante precursor de como a ciência econômica padrão provavelmente será feita nos próximos anos. 